
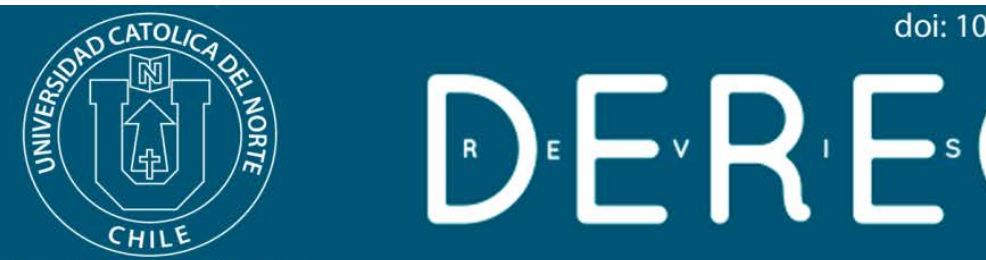

\title{
La legislación chilena no es contraria al cuidado personal compartido con oposición de uno de los padres
}

\section{The chilean legislation is not contrary to shared custody with the opposition of one of parents}

Rodrigo Barcia Lehmann* (D) https://orcid.org/0000-0003-1021-446X

* Universidad Finis Terrae, Santiago, Chile. Profesor. Doctor en Derecho Civil, U. Complutense.

(1) rbarcia@uft.cl

(cc) BY

\section{Resumen:}

Se justifica el cuidado personal compartido, aún con oposición de uno de los padres, y aún a falta de ley que la establezca de forma expresa. El cuidado personal compartido se presenta como una manifestación fundamental del interés del niño, niña o adolescente, sobre todo en los regímenes de custodia exclusiva Palabras Clave: Custodia; Corresponsabilidad de los padres; Igualdad de los padres; Interés superior del niño.

\begin{abstract}
:
Shared custody is justified, even with the opposition of one of the parents, and justifies its application in the absence of a law that expressly establishes it. Shared custody is presented as a fundamental manifestation of the child's interest, especially in exclusive custody regimes.

Keywords: Custody; Parental coresponsibility; Equality of parents; The best interests of the child.
\end{abstract}




\section{Introducción}

La mayoría de los países abandonaron la regla de la preferencia materna, otorgando el cuidado personal a cualquiera de los padres, conforme al interés superior del niño, niña o adolescente, primero mediante aplicaciones jurisprudenciales y luego, a través de reformas legales. En estos regímenes la custodia era exclusiva para uno de los padres; pero, conforme a los principios del interés superior del niño, niña o adolescente y de corresponsabilidad de los padres se asignaron deberes y facultades de filiación exclusivos y conjuntos ${ }^{1}$. El establecimiento de deberes y facultades para el padre no custodia en los hechos condujo a que estos regímenes fueran evolucionando hacia regímenes de corresponsabilidad conjunta, primero, y de custodia compartida, después. Esta evolución se ha generado en el Derecho comparado de forma natural desde que la custodia compartida, como régimen especial - aunque los padres mantenían disputas en muchos casos,- era la mejor opción para el niño, niña o adolescente. El éxito de la custodia compartida ha llevado a que varios ordenamientos jurídicos se inclinaran definitivamente por el cuidado conjunto o la custodia compartida, a través de reformas legales, como régimen legal, supletorio y privilegiado o a lo menos como régimen especial en los Derechos que la regla general, legal y supletoria es la custodia unilateral. En la mayoría de los países la custodia compartida primero se adoptó vía jurisprudencial, y luego, se estableció como régimen especial con oposición de uno de los padres. Chile, a raíz de la Reforma del 2013, se encuentra en un estadio intermedio, por cuanto dicha ley suprimió la regla de la superioridad materna y ha aumentado sustancialmente los deberes y facultades del padre no custodio, y los conjuntos a través de la corresponsabilidad (artículo 224 Código Civil de Chile). Sin perjuicio de lo cual, la regulación del cuidado personal compartido ha dado lugar a serios problemas de aplicación e interpretación, desde que la Reforma sólo ha regulado la custodia compartida de común acuerdo. En el presente trabajo para encontrar soluciones al ordenamiento jurídico chileno se ha recurrido a Derechos que no consideran el cuidado personal compartido como régimen legal y supletorio ${ }^{2}$. Y se ha desarrollado especialmente el Derecho español por

\footnotetext{
${ }^{1}$ En este trabajo se utiliza la expresión deberes- facultades para referirse a los efectos de la relaciones de filiación, aunque la doctrina suele señalar varias acepciones a este respecto, véase Espejo (2016, p. 209).

${ }^{2}$ Se ha dejado fuera del presente trabajo los países que han adoptado la custodia compartida como régimen legal, supletorio y privilegiado. Así ha sucedido en Italia, Francia, Alemania, Australia y en los Estados Unidos.

La Ley 54/2006 (reforma al art. 155 Codice), incorporaría al Derecho italiano la custodia compartida como régimen legal y supletorio. $Y$, a su vez, dicha Reforma Legal sólo autorizaría al juez a establecer la custodia exclusiva como régimen excepcional, por cuanto requiere una resolución del juez sustentada en el interés superior del niño. En Francia, el artículo 373-2-11 ${ }^{\circ}$ del Code (modificado por la Ley 2002-305, de 4 de marzo del 2002), estableció la autoridad compartida. Asimismo, contempló que el juez debe valorar prioritariamente la posibilidad de que los hijos permanezcan bajo el cuidado de ambos progenitores, pudiendo llegar a imponer la résidence alternée aun cuando ninguno de los padres este de acuerdo. En Alemania también se impondría la custodia compartida, como régimen legal supletorio, mediante la Reforma de abril de 2013 (actual §1626 a) BGB). En los Estados Unidos de Amé-
} 
cuanto allí en un comienzo se aplicó el cuidado personal compartido con oposición a través de la jurisprudencia ${ }^{3}$, generándose argumentos contra esta figura similares a los nuestros (como ocurrió respecto del conflicto de los padres como fundamento del rechazo de la figura). Posteriormente en España se reguló expresamente la guarda compartida con oposición de uno de los padres ${ }^{4}$. Sin perjuicio de lo anterior, es necesario aclarar que tanto la custodia unilateral, como la compartida, independientemente de la regla general legal y supletoria que se adopte, deben convivir ${ }^{5}$. Así, en Chile, aunque la custodia unilateral sea el régimen legal y supletorio, la custodia compartida es una herramienta a la que puede recurrir el juez, aunque sólo sea como un régimen especial, en cuanto dicho cuidado proceda conforme a los principios del interés superior del niño y de la corresponsabilidad ${ }^{6}$.

A continuación se analizarán la legislación de España, del Reino Unido, de algunos países de Latinoamérica y de Chile respecto de la custodia compartida. Son especialmente relevantes el Reino Unido y España, por cuanto estos dos ordenamientos jurídicos tienen un sistema de asignación de guarda y custodia unilateral en el caso español- ; de "parental responsability", con o sin "shared residence" en el caso del Reino Unido, en que el juez puede recurrir a la cuidado compartida con oposición de uno de los padres. Sin perjuicio de lo cual, la forma de regulación del cuida-

rica las legislaciones federales optan por establecer el cuidado conjunto como regla legal o supletoria o a lo menos habilitan a los jueces para dar lugar a órdenes de custodia compartida. En este sentido lo que se pretende es establecer unas verdaderas presunciones a favor del cuidado personal compartido. Así, Rhoades y Boyd (2004), señalan que en Australia, a mediados de los 90, se adopta la custodia compartida y se está discutiendo el establecer una presunción legal de tiempo compartido. En el Congreso se ha discutido la posibilidad de establecer: "A rebuttable presumption of 'equal time with each part'" (p. 120). Sin embargo esta opción no ha prosperado por cuanto se ha estimado que es preferible dejar la decisión en los tribunales, que deben aplicar el principio del interés superior del niño. Así, se perfeccionaría la presunción de igual responsabilidad parental compartida mediante la modificación del 2006 en la Family Act (Shared parental responsibility). Ver: la reforma del 2006 en numeral 30 Subsection 65D(2), en http://bit.ly/2oCwx5h. (Sanford, 2011, p.111)

${ }^{3}$ Las críticas a la Reforma española del 2005 se centraron precisamente en que no se haya establecido como régimen legal y judicial supletorio a la custodia compartida. Cruz (2012, p.184) trae a colación la regulación del Estado de Maine en el cual ambas formas de custodia conjunta son las supletorias y el Juez puede conceder la custodia indistinta, pero dando las razones para negar la coparticipación de los derechos y responsabilidad parentales. Maine Revised Statutes Annotated, title 19-A; Domestic Relations § 1653, sub-§1 de 21 de septiembre del 2001.

${ }^{4}$ Sin perjuicio de lo señalado, respecto de España se dejará fuera de este trabajo las legislaciones forales que han establecido la custodia compartida como régimen legal y supletorio. Así, el Decreto Legislativo $\mathrm{N}^{\circ} 1$ de 2011, de 22 de marzo, del Gobierno de Aragón dispone que a falta de pacto entre los progenitores, el juez adoptará de forma preferente la custodia compartida en interés de los hijos e, igual solución consagran la ley valenciana (Ley valenciana $N^{\circ} 5$ de 2011) y el Código Civil Catalán (art. 233-9).

${ }^{5}$ A este respecto Guilarte (2014) señala que: "... ni la guarda exclusiva ni la guarda compartida o alternativa son el molde perfecto adaptable a todas las situaciones que pueden originarse en la realidad social, que es rica en diversidad..." (p. 27).

${ }^{6}$ A este respecto Picontó (2010, p. 74) señala que adaptar la distribución de la guarda y custodia atendiendo a la dinámica de cada familia sería lo óptimo, evitando aplicar el mismo modelo a todas las familias. Ello con la finalidad de lograr soluciones realizables, respetuosas con las preferencias de cada familia, que permitan la continuidad de las relaciones de los hijos con sus padres, que atiendan a los acuerdos anteriores a la ruptura y que mitiguen el enfrentamiento entre ellos.

Rev. derecho (Coquimbo, En línea) 2019, 26: e3596 
do compartido es diferente. En el caso español se regulan expresamente la custodia compartida de común acuerdo por los padres y con oposición de uno de ellos. En cambio, en el Reino Unido se da lugar a la custodia compartida con oposición, a través de las denominadas "shared order residence". En el Derecho chileno sólo está expresamente regulada de forma expresa la custodia compartida de común acuerdo. El presente trabajo sugiere revisar la posición de los tribunales chilenos que han estimado que la custodia compartida con oposición no procede. A este respecto, los Derechos español y del Reino Unido son especialmente relevantes desde que, como en Chile y a diferencia de Europa, la regulación general no es la custodia compartida no es un régimen privilegiado, legal y supletorio, sino a la unilateral a favor del padre custodio.

\section{La situación española}

Gete-Alonso y Solé señalan que, conforme a la Ley $N^{\circ} 15 / 2005$, los casos en que es posible acordar la custodia compartida, son los siguientes: cuando los padres lo solicitan en la propuesta de convenio regulador (separación o divorcio de mutuo acuerdo); en un proceso contencioso, en que los padres lleguen al acuerdo sobre la custodia compartida en el transcurso del procedimiento, dejando de ser contencioso y, por último, que el Juez la acuerde, excepcionalmente, si lo pide solamente uno de los progenitores y sólo de esta forma se proteja el interés superior del menor. En los dos primeros casos, el Juez podrá no otorgarla si considera que perjudica el interés del menor, no obstante existir acuerdo entre los padres. A continuación se analizará especialmente la etapa jurisprudencial intermedia en que los tribunales, sin texto de ley, concedieron el cuidado compartido.

\subsection{Evolución desde la negativa a la custodia compartida con oposición de uno de los padres hasta su consagración como régimen excepcional en el Código Civil Español}

Picontó (2010, p. 46) señala que los problema de igualdad, con relación al cuidado personal de los padres, no se plantearon en la Reforma de la Ley Nº 30/1981, por cuanto existía un cierto consenso entre abogados y jueces que ella correspondía a la madre, sobre todo respecto de los hijos más pequeños ${ }^{7}$. Los temores de la doc-

\footnotetext{
${ }^{7}$ Luego, el Código Civil Español limitó la coparentalidad en el ejercicio a los supuestos de convivencia y para las situaciones de ruptura preveía el ejercicio exclusivo de la patria potestad, que correspondía al progenitor en cuya compañía quedaban los hijos, con lo que se pretendía asegurar la unidad de dirección y preservar a los menores de posibles conflictos. Pero, esta solución debió modificarse dado el aumento de separaciones y divorcios. A este respecto Guilarte (2014) señala que: "Este esquema legal no responde a la nueva realidad familiar, caracterizada por un número creciente de divorcios y la normalización social de las rupturas, ya no se trata de mantener a los menores alejados del conflicto, sino de garantizar su derecho a relacionarse y a ser educado por sus dos padres" (pp. 21-22).
} 
trina española frente a esta figura, antes de la Reforma introducida por la $\mathrm{N}^{\circ}$ Ley 15/2005 al Código civil Español, se pueden apreciar en las palabras de Picontó (2010), que señalaba: "... establecer una medida como la custodia compartida alterna a falta de acuerdo de los padres, bien judicialmente o como norma legal preferente, cuando no se corresponde con el estilo de vida y la división del trabajo de muchas familias españolas puede ser arriesgada y provocar dificultades en aquellas parejas que antes de la crisis no venían compartiendo las tareas del cuidado de los hijos"(p. 57). La crítica a la custodia compartida en el fondo se centra en su establecimiento como régimen legal y supletorio ${ }^{8}$. Pero, incluso, antes de la Ley $N^{\circ} 15 / 2005$, la jurisprudencia mayoritaria rechazaba la custodia compartida con alternancia de domicilios, argumentando básicamente su falta de regulación legal y contrariedad al principio del interés del menor, dada su valoración conectada a una necesaria estabilidad y no a un cambio de domicilio ${ }^{9}$. Incluso se cuestionó la custodia compartida en casos en que había sido acordada por los padres en el convenio regulador. Los jueces entendían que era conveniente atribuir la guarda y custodia en exclusiva a uno de los progenitores, a quien además se le otorgaba la vivienda familiar, debiendo el otro pagar una pensión alimenticia y se le concedía un derecho de comunicación y visita (Picontó, 2010, pp. 6061). Esta oposición a la custodia compartida, empieza a diluirse por las Sentencias del Tribunal Constitucional español, 2a Sala, 4/2001, de 15 de enero, y una serie de sentencias de los tribunales civiles que otorgan la custodia a ambos padres (Pinto Andrade, 2009) ${ }^{10}$. Los sustentos jurisprudenciales para concederla fueron los principios

\footnotetext{
8 Poussin y Lamy (2005) son de la opinión que ante los problemas que acarrea el divorcio y el cuidado de los hijos, la custodia compartida es una solución posible: "... pero no es ni la única ni la mejor. Más bien es la solución menos mala para que se respete el derecho del hijo a crecer cerca de sus dos progenitores" (p.17); que "...algunas familias 'pionera' ya practicaban la custodia compartida antes de marzo de 2002, pero esta práctica se realizaba siempre de forma amistosa, sin el aval de la justicia. Después de esta fecha, los jueces no han aplicado demasiado la ley: sólo una quinta parte de los padres en trámite de divorcio solicita este régimen de custodia. En países como Estados Unidos, por ejemplo, la aplicación de este régimen es mucho más frecuente. El estado de California favorece especialmente la custodia compartida y, en otros estados (Montana, Kansas, Connecticut) es considerada una solución satisfactoria, y la practican en torno al $40 \%$ de las parejas", y que la custodia compartida rompe con la dinámica de vencedor y vencido, ya que pone a los dos progenitores en situación de paridad desde el principio" (pp. 28-29), Villagrasa (2010, p.83) también se encuentra contra del establecimiento de la custodia compartida como régimen legal y supletorio y señala, de forma muy clara, que imponer coactivamente el sistema de la custodia compartida alterna o, mejor expresado, la guarda sucesiva o alternativa, es inviable, si no se dan unas premisas dirigidas a garantizar el interés superior del menor. Pues exige un grado de consenso, respeto y colaboración entre los progenitores. Así, los referidos autores reconocen que el cuidado personal compartido puede adecuarse de una buena forma al interés superior del niño, pero ello dependerá de las circunstancias.

${ }^{9}$ Sin perjuicio, que al poco andar de este siglo, como destaca Campuzano (2004 pp. 2485, 2488-2502) mediante un estudio jurisprudencial, la jurisprudencia española comenzó a decretar la custodia compartida en la medida que ella fuese la decisión más favorable para el adecuado desarrollo del menor. ${ }^{10}$ Zarraluqui (2003), en igual sentido, señala que: "La custodia alternativa es una fórmula que en ciertos casos puede ser de indudable beneficio para los menores, respetando una posición equitativa de ellos respecto de ambos progenitores y ello, incluso, sin necesidad de que los periodos en que se encuentren con uno y otro sean aritméticamente iguales, cuando las circunstancias así lo aconseje" (p. 183). Gete-Alonso y Solé (2014, p. 168) señalan, respecto al interés superior del menor, que a menudo se encuentra teñido de apreciaciones subjetivas difíciles de superar. No obstante, predomina la opinión de que en materia de custodia sobre los menores, el bien del menor pasa por ver satisfecho su derecho de relacio- 
del interés superior del niño y de la igualdad de los padres, muchas veces planteado como un criterio de adecuación a la realidad ${ }^{11}$; $y$ de forma escalonada por acuerdo de los padres; con oposición de uno de ellos e incluso de oficio (Montero, 2001). Así, parte de la doctrina y la jurisprudencia española por mucho tiempo se inclinaron a entender que, por regla general, la custodia compartida exigía común acuerdo de los padres, o a lo menos el que los padres tuviesen una buena relación entre ellos ${ }^{12}$. Para esta doctrina la responsabilidad parental tenía que ver con la capacidad de llegar a acuerdos o de obstruirlos por parte de los padres (Sentencias Audiencias Provinciales Españolas, Barcelona, sección 12, n²6/2007, de 12 de enero).

La situación no varió sustancialmente con la Reforma del 2005. Sin perjuicio de lo cual, como destaca Guilarte, la Sentencia del Tribunal Supremo Español, de 29 de abril de 2013, habría generado un cambio en esta tendencia. En palabras de la referida autora, la sentencia al casar el fallo recurrido, manteniendo la sentencia recurrida, justifica la denegación de la custodia compartida con base en la falta de concurrencia de los criterios fijados en su doctrina jurisprudencial. Y no, como hace la sentencia recurrida, en una consideración negativa del régimen de custodia compartida: "dados los términos restrictivos que en ese sentido figuran en el Art. 92-8 Código Civil de Chile, cuyo tenor literal es claro al establecer que si los dos padres no están de acuerdo (supuesto del apartado 5) dicha modalidad sólo se acordará excepcionalmente y con informe favorable del Ministerio Fiscal" (Guilarte, 2014, pp. 36-37). Así, en la actualidad, la custodia compartida procede a petición conjunta por ambos progenitores y excepcionalmente a instancia de uno de los padres, con los demás requisitos exigidos, como se desprende de lo resuelto por la Sentencia del Tribunal Supremo Español de 19 de abril de 2011. Sin perjuicio de lo cual, la aplicación de la custodia compartida con oposición de uno de los padres, antes de la Reforma del 2005, fue bastante limitada ${ }^{13}$.

narse y ser atendido tanto por su padre como por su madre y, en consecuencia, por no ser privado de la compañía de ninguno de ellos aunque hayan decidido dejar de convivir. Produciéndose una evolución en la custodia compartida, que de tenerse como contraria al interés del menor por perjudicar su estabilidad física y emocional, ha pasado a ser la medida más recomendada para afrontar con las mínimas consecuencias la separación de los padres y la ruptura familiar.

${ }^{11}$ Respecto del criterio de adecuación a la realidad, Villagrasa (2010, p. 95) es de la opinión que para evitar la afectación de la crisis de pareja a los menores, la clave es comprobar quién o quiénes se han encargado de su cuidado con anterioridad a la ruptura. Una vez hecho se debe proceder a mantener la guarda en esa proporción, en caso de desacuerdo. Ello, sin perjuicio, que la guarda pueda ser compartida siempre que pueda mantenerse una comunicación fluida y una relación cordial entre los progenitores.

${ }^{12}$ En este sentido se puede consultar a Rivera Álvarez $(2006$, p. 11) que se opone a la posibilidad que el juez decrete la custodia compartida de los hijos, si ninguno de los padres se lo ha solicitado, por cuanto de fracasar dicho régimen ello podría ir en perjuicio del hijo.

${ }^{13}$ Cruz $(2012$, p.253) señala que las razones por las que las sentencias negaban dicha posibilidad eran de diversa índole, señalándose entre ellas: a) residencia de los progenitores en países o lugares distintos; b) falta de mutuo acuerdo; c) falta de colaboración y armonía entre los padres; d) trastorno y perjuicios en la estabilidad el menor, pérdida de hábitat y armonía que acaban afectándolo en su desarroIlo integral; e) corta edad; f) invasión de la esfera privada; g) interés superior del niño en sentido abs- 
A continuación se analizará la actual regulación de la custodia compartida con oposición. El artículo 92 del Código Civil Español ejercicio compartido de la guarda y custodia mediante acuerdo de los padres (apartado 5) y guarda y custodia compartida con oposición de uno de los padres (apartado 8). La Ley N 15 del 2005 reguló específicamente la custodia compartida con oposición de un padre, en el artículo 92, párrafo $8^{\circ}$ del Código Civil Español, en los siguientes términos: "8. Excepcionalmente, aun cuando no se den los supuestos del apartado cinco de este artículo, el Juez, a instancia de una de las partes, con informe favorable del Ministerio Fiscal, podrá acordar la guarda y custodia compartida fundamentándola en que sólo de esta forma se protege adecuadamente el interés superior del menor" ${ }^{14}$.

Un aspecto que ha generado discusión en la dogmática española respecto de la norma precedente es su excepcionalidad. Y ello se tradujo, en un principio, que la custodia compartida con oposición debía ser la única forma de plasmar el interés superior del niño. Por lo que de haber otra posibilidad, el juez debía adoptarla. Naturalmente que esta interpretación atentaba contra el interés superior del niño por cuanto de forma abstracta obligaba a los jueces a desechar esta posibilidad ante, por ejemplo, un régimen de comunicación ampliada. Ni la dogmática española ni la jurisprudencia han seguido esta interpretación ${ }^{15}$. Delgado (2010), al respecto, señala que un criterio razonable de interpretación es el que entrega el IV Encuentro de Magistrados y Abogados de Familia, que señala: "El establecimiento de un régimen de custodia conjunta a solicitud de uno solo de los progenitores, al amparo de lo dispuesto en el apartado 8 del artículo 92 del CC, no exige fundamentar que sólo con esta modalidad de custodia se protege adecuadamente el interés del menor, bastando razonar que es la opción de custodia considerada más beneficiosa para el menor en el caso concreto.

Se insta del legislador una modificación del precepto en tal sentido". (pp. 89-91).

La discusión ha sido zanjada por la jurisprudencia del Tribunal Supremo español que ha resuelto que la custodia compartida no se puede entender como régimen excepcional a pesar de lo que prescribe el artículo $92.8^{\circ}$ del Código Civil Español ${ }^{16}$. Ello desde que "concurran alguno de los criterios antes explicitados y la redacción de dicho artículo no permite concluir que se trate de una medida excepcional, sino que al contrario, debería considerarse la más normal, porque permite que sea efectivo el

tracto; h) la preferencia del régimen de cuidado indistinto con relación directa y regular para el padre no custodio; i) previa custodia compartida perjudicial para el hijo y j) rechazo a la custodia compartida por no estar establecido en la ley.

${ }^{14}$ La inclusión del Informe Fiscal para la custodia compartida con oposición de uno de los padres, del art. 92.8 del Código Civil Español se debe a una inclusión del Grupo Socialista. (Miranda, 2009).

15 Pérez Conesa (2016, p. 47).

${ }^{16}$ Cft Alascio, L. (2011, p. 22) con Bodelón (2010, p. 138.)

Rev. derecho (Coquimbo, En línea) 2019, 26: e3596 
derecho que los hijos tienen a relacionarse con ambos progenitores, aun en situaciones de crisis, siempre que ello sea posible y en tanto en cuanto lo sea"17.

Para concluir, la discusión actual sobre la custodia compartida con oposición de un padre se soluciona en el artículo 92 bis. $1^{\circ}$ del Código Civil Español del Anteproyecto de Ley española, en actual tramitación sobre el ejercicio de la corresponsabilidad parental en caso de nulidad, separación y divorcio, otorgando la facultad al juez de conceder el cuidado personal compartido con oposición en los siguientes términos:
"1.- El Juez podrá acordar, en interés de los hijos, que su guarda y custodia sea ejercitada por uno solo de los progenitores o por los dos, de forma compartida. Podrá establecer, si lo considera con- veniente para la protección del interés superior de los hijos, el ejercicio compartido de su guarda y custodia cuando así lo solici- ten los padres en la propuesta de convenio regulador, cuando ambos lleguen a este acuerdo en el transcurso del procedimiento o cuando, no mediando acuerdo, cada uno de ellos inste la cus- todia para ambos o para si" 1819 .

A pesar que este Proyecto parece ser un avance sólo refleja la realidad actual, como se desprende por la jurisprudencia posterior a la Sentencia del Tribunal Supremo Español de 29 de abril del 2013. Así, este Proyecto ha sido fuertemente criticado por la doctrina ${ }^{20}$.

\footnotetext{
${ }^{17}$ Alcázar Ruiz (2014, p. 273) señala que en España las cifras de cuidado compartido han ido aumentando, pero que todavía la custodia sigue siendo de forma generalizada a favor de la madre. Así, es compartida en un 10,5\% en el año 2010; 12,3\% en 2011 y 14,6\% en 2013, y la custodia materna en esos mismos años es de 83.2\% en 2011, 81,7\% en 2012 y $75.1 \%$ en 2013.

${ }^{18}$ Anteproyecto de ley sobre el ejercicio de la corresponsabilidad parental en caso de nulidad divorcio separación $(2013$, p.19)

${ }^{19}$ La Reforma también prevé la introducción del artículo 92 bis al Código Civil que, de acuerdo con la literalidad de su exposición de motivos, "tiene como objeto introducir los cambios necesarios para conseguir un sistema donde desaparezcan las rigideces y las preferencias por la custodia monoparental del actual artículo, pero sin establecer la custodia compartida como preferente o general".

${ }^{20}$ De este modo, Gete-Alonso y Solé (2014) señalan que: "Nosotros apostamos por una reforma más ambiciosa que considere la custodia compartida como regla general y preferente en la solución de las crisis de convivencia, salvo que la custodia individual sea más conveniente para el hijo-en la línea de las normativas de Aragón y la Comunidad Valenciana-, y que podría representar un elemento fundamental para iniciar un cambio profundo en la solución de estas situaciones más acorde con los derechos fundamentales de todas las personas implicadas y, al mismo tiempo, podría incidir en los comportamientos de ambos progenitores para con sus hijos constante la convivencia, es decir, antes de iniciarse la crisis de pareja, fomentando la corresponsabilidad y la paternidad y maternidad responsables"(p. 171).
} 


\subsection{Presupuestos de la custodia compartida con oposición de uno de los padres, con especial mención a la conflictividad entre los padres}

El artículo $92.8^{\circ}$ del Código Civil Español no ha establecido cuáles son las circunstancias concretas que el juez debe valorar para dar lugar a la guarda compartida con oposición en el interés superior del niño (Sentencia del Tribunal Supremo Español, 8 de octubre del 2009, RC núm. 147/2006) ${ }^{21}$. Por ello la jurisprudencia y la doctrina han establecido ciertas condiciones de concurrencia.

En cuanto a la jurisprudencia, para Pinto los tribunales han establecido los siguientes criterios para conceder el cuidado compartido: a) La relación de los progenitores entre sí y con sus hijos; b) La proximidad geográfica entre domicilios de los progenitores; c) La similitud en los modelos educacionales de los padres; d) La relativa disponibilidad profesional hacia los hijos; e) La custodia compartida como factor de inestabilidad; f) La preocupación por el rendimiento escolar y g) La promisión de las relaciones interpersonales del niño (Pinto Andrade, 2009, pp. 75-79). Gete-Alonso y Solé (2014) plantean una posición mucho más restrictivas en el otorgamiento de la custodia compartida, al exigir una gran cantidad de condiciones. Ellas serían conforme a la Sentencia de la audiencias provinciales española de Córdoba, de 24 de abril de 2006 (JUR 2006/230967), las siguientes: a) Muy bajo nivel de conflicto entre los progenitores, b) buena comunicación y cooperación entre ellos, c) residencias cercanas o geográficamente compatibles, d) rasgos de personalidad y carácter del hijo y los padres compatibles, e) edad del menor que permita su adaptación, f) cumplimiento de los progenitores de las obligaciones económicas, g) respeto mutuo por ambos progenitores, h) que no haya excesiva judicialización de la separación, i) existencia de un vínculo afectivo del menor con ambos padres, j) que ambos progenitores estén de acuerdo con la alternativa de custodia compartida, en definitiva características de los progenitores como madurez personal y capacidad para separar el plano de la relación de pareja de sus roles como padres ${ }^{22}$.

La Sentencia del Tribunal Supremo Español del 24 de abril de 2014, que resuelve el recurso de casación: Núm.: 2983/2012, fija los criterios de atribución del régimen de custodia compartida, señalando que debe estar fundada en el interés del niño, niña o adolescente que van a quedar afectados por la medida que se deba tomar y que las razones que deben considerarse son la práctica anterior de los progenitores en sus relaciones con el menor y sus aptitudes personales; los deseos manifes-

\footnotetext{
${ }^{21}$ Ello a pesar que establece algunas reglas procesales para que la custodia compartida con oposición proceda, como requerir el informe del Ministerio Fiscal, y oír a los menores que tengan suficiente juicio cuando se estime necesario de oficio o a petición del Fiscal, partes o miembros del Equipo Técnico Judicial, o del propio menor, valorar las alegaciones de las partes vertidas en la comparecencia y la prueba practicada en ella, y la relación que los padres mantengan entre sí y con sus hijos.

${ }^{22}$ Las autoras señalan que la falta de estos requisitos ha fundamentado la denegación de la custodia compartida. Gete-Alonso y Solé (2014 p. 163).
} 
tados por los menores competentes; el número de hijos; el cumplimiento por parte de los progenitores de sus deberes en relación con los hijos y el respeto mutuo en sus relaciones personales; el resultado de los informes exigidos legalmente $y$, en definitiva cualquier otro que permita a los menores una vida adecuada, aunque en la práctica pueda ser más compleja que la que se lleva a cabo cuando los progenitores conviven (Seijas, Arroyo y Baena, 2015, p. 119).

La doctrina española ha sostenido que pueden establecerse a priori determinados presupuestos objetivos que favorecen un sistema de custodia compartida, pero ello no significa que de concurrir todos y cada uno de ellos, resulte siempre beneficioso para el menor dicho sistema de custodia, ni que, de no concurrir alguno, deba denegarse sin más (Delgado, 2010, p. 202). Los criterios son los siguientes: las aptitudes personales de los progenitores, la proximidad de los domicilios de los padres, medios materiales suficientes, la edad de los niños y su voluntad (Guilarte, 2014, pp. 42-50), los motivos por los que se elige dicha opción o se opone a ella y, por último, el resultado de los informes exigidos legalmente. Estas circunstancias se pueden agrupar de la siguiente forma:

a. En cuanto a las aptitudes personales de los progenitores: la capacidad de los padres para celebrar y mantener acuerdos de cooperación activo y de corresponsabilidad, la capacidad de los padres para mantener un modelo educativo común, baja conflictividad entre los padres y la relación previa y coetánea a la ruptura de los padres con sus hijos. En este sentido se valora positivamente la capacidad de cooperación y ayuda muta entre los padres. Poussin y Lamy (2005, p. 53-60) agregan, como criterio de admisibilidad, el análisis de los motivos últimos por los que se elige la custodia compartida por el solicitante.

Tal vez, el criterio que ha generado una mayor discusión en la doctrina es el grado de conflictividad entre los padres como criterio de exclusión del cuidado personal compartido. En un principio la exigencia de este requisito fue muy estricta. Así, la jurisprudencia española hasta del 2007 seguía esta tendencia, entendido que la mala relación entre los padres es una causa de la denegación del régimen de custodia compartida (Sentencias Audiencias Provinciales españolas, Gerona, $2^{\mathrm{a}}, 9.02 .2000$; Barcelona, $12^{\mathrm{a}}, 8.06 .2000$ y 16.10.2007, 22a, 9.10.2006 y 18a, 12.01.2006; Zaragoza, 4a, 24.07.2006 у 14.11.2006; Madrid, 22a , 22.09.2006, 3.10.2006, 2.03.2007, y 9.03.2007; León, 3a, 13.10.2006 y Vizcaya, 4a, 20.03.2007). En este sentido Miranda (2009) sostiene que: "Ios tribunales pueden conceder la custodia compartida en los casos en que aprecien condiciones especiales en ambos progenitores, puesto que lo contrario, la ausencia de una regulación estricta de las obligaciones derivadas de la responsabilidad parental, como ocurre con otras modalidades de custodia, coloca a los hijos menores en situaciones de grave riesgo, ante la ausencia de crite- 
rios comunes y la multiplicación de conflictos que pone de relieve la casuística en la ejecución de sentencias de muy difícil solución rápida y eficaz", y agrega, matizando la opinión precedente, que la custodia compartida no procede en caso de "una extrema situación de conflictividad entre los progenitores"23. A igual conclusión arriba en Chile, Illanes (2016, p. 141). Este parece ser el criterio correcto, en caso que el origen del conflicto provenga de la actitud de ambos padres y ello perjudique al niño, niña o adolescente ${ }^{24}$. En la actualidad se ha impuesto que el grado de tensión entre los padres no sea óbice, en principio, para decretar la custodia compartida con oposición del otro padre, pero en la medida que la tensión sea la propia de una situación de crisis. Así, Poussin y Lamy (2005) no están de acuerdo en considerar la custodia compartida viable únicamente cuando los padres se lleven bien. $Y$ a este respecto señalan que dicho argumento entraña el peligro de hacer inviable esta figura, ya que un adulto que no esté de acuerdo con la custodia compartida puede declarar ante el juez que no mantiene comunicación con su ex pareja, con el fin de echar por tierra el régimen de alternancia en la custodia. Ello sería un punto a favor del padre beligerante, en circunstancias de que a quien se debe recompensar es al padre conciliador. Y por ello proponen que el juez de familia, verificando tensión o conflicto entre los padres, pueda imponer una custodia compartida provisional, por ejemplo de seis meses, y una vez transcurridos, decide si perpetuar o no el sistema ${ }^{25}$. En igual sentido, Delgado (2010) - refiriéndose a algunas sentencias que exigen que los padres se lleven bien- utiliza la siguiente parte de una sentencia para concluir lo referente al sistema antes referido y a la conflictividad de los padres: "Esta conclusión se ve matizada por sentencias que admiten que la conflictividad entre los progenitores no obsta para instaurar el régimen de guarda y cuidado compartido" (pp.171-172). Sin embargo, no se puede desconocer que un alto grado de conflictividad entre los padres es un aspecto gravitante en la custodia compartida; pero la solución del caso concreto exige poder precisar, sí aún en estos casos, la custodia compartida va en el mejor interés del niño, niña o adolescente, lo que exige poder analizar tan-

\footnotetext{
${ }^{23}$ Seijas, Arroyo y Baena (2015) se refieren a una Sentencia del Tribunal Supremo Español de 30 de octubre de 2014, recurso de casación: Núm.: 1353/13, que resuelve en este sentido: “... la custodia compartida conlleva como premisa la necesidad de que entre los padres exista una relación de mutuo respeto que permita la adopción de actitudes y conductas que beneficien al menor, que no perturben su desarrollo emocional y que pese a la ruptura afectiva de los progenitores se mantenga en un marco familiar de referencia que sustente un crecimiento armónico de su personalidad" (pp. 120-121).

${ }^{24}$ Bodelón (2010, p. 137), que escribe desde el feminismo, es contraria a conceder la custodia compartida en caso de conflictividad de los padres, y a este respecto recomienda la custodia exclusiva que limite la posibilidad de nuevos conflictos.

${ }^{25}$ Poussin y Lamy (2005) exigen que los padres un mínimo de buen entendimiento en lo que respecta a las decisiones relacionadas con la educación del hijo; tener relativa disponibilidad profesional y por último analizar los motivos últimos por los que se elige dicha opción.
} 
to su opinión como determinar las habilidades parentales de los padres ${ }^{26}$. A igual conclusión se llega en el Derecho Argentino ${ }^{27}$.

b. La proximidad de los domicilios de los padres. Delgado (2010) señala que el hecho de que los padres residan en domicilios diferentes, especialmente cuando éstos están a gran distancia o en localidades diferentes, puede representar un obstáculo para acordar una guarda compartida ${ }^{28}$.

c. La opinión del niño, niña o adolescente.

Existe cierto consenso en que el niño, niña o adolescente debe ser oído, dependiendo de las edades de forma directa o indirecta (si es muy pequeño). La edad en que la opinión del niño, niña o adolescente es tomada en cuenta de una forma más o menos decisiva es de 12 años $^{29}$. En la valoración de dicha decisión se debe tomar en cuanto su madurez, y ella debe ser pondera por el juez conforme al interés superior. Sin embargo, pasada cierta edad los jueces suelen tomarla como el antecedente de mayor relevancia para conceder la custodia compartida ${ }^{30}$.

\footnotetext{
${ }^{26}$ En este sentido es sumamente interesante la Sentencia Del Tribunal Supremo Español, de 16 de octubre de 2014, que, resolviendo un recurso de casación: Núm.: 683/2013, resuelve lo siguiente: "A la vista de lo expuesto hemos de declarar que en la sentencia recurrida se infringe la doctrina jurisprudencial, dado que la tensa situación que concurre en los cónyuges no consta que sea de un nivel superior al propio de la situación de una crisis conyugal. Por otro lado se acredita la favorable disposición de los menores, la gran aptitud de ambos padres para ostentar la custodia y que se abstienen de predisponer negativamente a los hijos, todo lo cual motiva la admisión del sistema de custodia compartida, como medida más favorable en interés de los menores" (Seijas, Arroyo y Baena, 2015, p. 117).

${ }^{27}$ El Código civil y comercial argentino, en caso de desacuerdo reiterado entre los padres y un nivel alto de conflictividad, faculta al juez para asignar temporalmente la custodia a uno de los padres. En este sentido Herrera (2015) señala que: "También se otorgan al juez facultades previsoras de futuros desacuerdos así como pacificadoras del vínculo familiar: si los conflictos son reiterados u ocurre cualquier otra causa que entorpezca gravemente el ejercicio de la responsabilidad parental, puede atribuirlo total o parcialmente a uno de los progenitores, o distribuir entre ellos sus funciones, por un plazo que no exceda dos años. Asimismo, con una clara función terapéutica en la familia en crisis, el juez puede ordenar medidas de intervención interdisciplinaria y someter los desacuerdos a mediación" (p. 378).

${ }^{28}$ Dentro de los argumentos jurisprudenciales encontramos los siguientes: los constantes cambios pueden generar inestabilidad en los niños; el cambio constante no supondría un beneficio sustancial para los menores; no se favorece la adaptación de los menores y repercute negativamente a nivel emocional y en su rendimiento académico; obliga a los niños a estar todo el día haciendo y deshaciendo las maletas y no se acostumbrarían a vivir ni en un sitio ni en otro; puede alterar perjudicialmente la normalidad de la vida de los menores; entre otros. Luego, el autor expone jurisprudencia en que, por la proximidad de los domicilios, la guarda compartida no representa impedimento.

${ }^{29}$ Skjørten y Barlindhaug (2007) realizan una interesante aplicación del artículo 12 de Convención sobre los Derechos del Niño en torno a las edades en que la opinión de los niños, niñas o adolescentes deben ser consideradas para los efectos de la residencia compartida. En dicho estudio se pudo apreciar como el nivel de educación de los padres llevaba a que los hijos pudiesen tener una opinión más madura. En este sentido los autores señalan que: "These studies suggest that the age of the child and the educational level of the parents are characteristics which impact the child's degree of co-decision" (p. 376). ${ }^{30}$ Guilarte (2014, p.47).
} 


\section{La situación Latinoamericana}

Latinoamérica está comenzado a admitir el cuidado personal compartido con oposición de uno de los padres, y además se está inclinando por el cuidado personal compartido como régimen privilegiado, es decir, legal y supletorio. Al igual que en el Derecho Europeo existen países como Brasil ${ }^{31}$ y Argentina, que establecen el cuidado compartido como régimen legal privilegiado y supletorio; pero los casos que nos interesan son aquellos en que el juez está facultado para decretar el cuidado personal compartido con oposición, como sucede con Perú y Uruguay que ha admitido la custodia compartida jurisprudencialmente, aunque de forma más bien excepcional.

Así, el Código Civil y Comercial Argentino establece el cuidado compartido en los siguientes términos:

"Artículo 651 [Reglas generales].

A pedido de uno o ambos progenitores o de oficio, el juez debe otorgar, como primera alternativa, el cuidado compartido del hijo con la modalidad indistinta, excepto que no sea posible o resulte perjudicial para el hijo".

A este respecto Pellegrini (2016) señala que: "Con cierta dificultad al comienzo y solo limitado a los acuerdos entre los progenitores, fue avanzando, incluso, a la imposición judicial. De allí que, por vía jurisprudencial, se perfiló un sistema tendiente a la 'tenencia compartida' - esto es, a favorecer tanto el ejercicio conjunto de la responsabilidad parental, inclusive en casos en que la convivencia material del hijo/a quedaba a cargo de un/a progenitor/a, como al efectivo reparto del tiempo de convivencia del hijo con ambos progenitores-. En algunos pocos casos se utilizó un sistema en el cual los hijos continuaban habitando el que fuera el hogar familiar y sus progenitores 'rotaban' el uso de tal vivienda; y en una amplia mayoría, fueron los hijos/as quienes compartían su vida en los dos nuevos hogares que la separación de sus progenitores generaba" (p. 484). En igual sentido Herrera destaca un fallo de la Suprema Corte de Justicia de la Provincia de Buenos Aires, de 05/12/2007, que a pesar de la falta de texto expreso de ley, establecería una custodia compartida, de oficio ${ }^{32}$. Las formas de custodia compartida

\footnotetext{
${ }^{31}$ Ver artículo 1584 del Código Civil Brasileño.

${ }^{32}$ En este sentido en el fallo se resuelve: "hace a la realización del principio de corresponsabilidad en el ejercicio de la autoridad en la toma de decisiones que a los progenitores concierne, efectivizar el mejor grado de desarrollo personal de los niños (arts. 6.2 y Preámbulo de la Convención sobre los Derechos del Niño; 3 incs. c] y d] y $9^{\circ}$ de la ley 26.061), en particular los derechos de educación y crianza focalizados a satisfacer sus necesidades y respetar las diferentes etapas evolutivas de los niños con sus propios requerimientos y expectativas (arts. 5, 14.2 y 18.1 y Preámbulo de la Convención de los Derechos del Niño), y garantizar que los niños por la madurez alcanzada, puedan expresar sus opiniones y ser escuchados (arts. $5^{\circ}$ y 12, primer párrafo, Convención de los Derechos del Niño)" (Herrera, 2015, p. 372).
}

Rev. derecho (Coquimbo, En línea) 2019, 26: e3596 
adoptada por la legislación argentina son: alternada e indistinta ${ }^{33}$. Sin perjuicio de lo anterior, como destaca Cajigal (2016): "en lo relativo al ejercicio de la responsabilidad parental, el nuevo C.C.C. establece como criterio general que corresponde a ambos progenitores en forma conjunta, convivan o no, sin perjuicio de que la norma regule diversas situaciones especiales. La mentada circunstancia de la atribución conjunta del ejercicio de la responsabilidad parental en ambos supuestos representa sin dudas una de las principales innovaciones de la nueva norma en la materia, ya que implica una clara diferencia respecto del código velezano, en el que sólo se establecía el ejercicio compartido cuando los padres convivían" (p. 291).

Los artículos 81 y 84 Código de los Niños y Adolescentes peruano regulan esta figura, siendo especialmente relevante la primera de estas normas, que establece que: "Cuando los padres estén separados de hecho, la tenencia de los niños, niñas o adolescentes se determina de común acuerdo entre ellos y tomando en cuenta el parecer del niño, niña o adolescente. De no existir acuerdo o si este resulta perjudicial para los hijos, la tenencia la resolverá el juez especializado dictando las medidas necesarias para su cumplimiento, pudiendo disponer la tenencia compartida, salvaguardando en todo momento el interés superior del niño, niña o adolescente ${ }^{1 / 34}$.

El Código de la Niñez y la Adolescencia uruguayo regula esta materia en los siguientes términos:

"Artículo 34 [Tenencia por los padres].

1) Cuando los padres estén separados, se determinará de común acuerdo cómo se ejercerá la tenencia (artículo 177 del Código Civil).

2) De no existir acuerdo de los padres, la tenencia la resolverá el Juez de Familia, dictando las medidas necesarias para su cumplimiento.

Artículo 35 [Facultades del Juez de Familia].

En caso de no existir acuerdo de los padres, el Juez resolverá, teniendo en cuenta las siguientes recomendaciones:

A. El hijo deberá permanecer con el padre o la madre con quien convivió el mayor tiempo, siempre que lo favorezca.

B. Preferir a la madre cuando el niño sea menor de dos años, siempre que no sea perjudicial para él.

\footnotetext{
${ }^{33}$ A este respecto Notrica y Rodríguez Iturburu (2015), señalan que: "las modalidades del cuidado personal estableciendo que el cuidado alternado es aquel en el que el hijo pasa períodos con cada uno de los progenitores, mientras que en el cuidado indistinto, el hijo reside de manera principal en el domicilio de uno de ellos, pero ambos comparten las decisiones y se distribuyen de modo equitativo las labores atinentes a su cuidado" (p.145).

${ }^{34}$ Código de los niños y adolescentes (2000).
} 
C. Bajo su más seria responsabilidad funcional, el Juez siempre deberá oíry tener en cuenta la opinión del niño o adolescente ${ }^{35}$

\section{La situación del Reino Unido}

Este país nos interesa por cuanto la custodia compartida no es un régimen legal supletorio, como en la mayoría de los países europeos, por lo que tiene una cierta semejanza con el sistema chileno. Además, ambos ordenamientos jurídicos establecen sistemas de corresponsabilidad, como regla general, y en ambos la custodia compartida no es el régimen legal supletorio; sin perjuicio de lo cual en el Reino Unido la custodia compartida se está comenzando a convertir de un régimen especial a un régimen general a través de los fallos de las Cortes.

La Children Act de 1989 introduciría en el Reino Unido una forma de corresponsabilidad a través de la "parental responsability". Nótese que esta figura, que corresponde a ambos padres, abarca fundamental aspectos de relevancia para la vida del niño, niña o adolescente ${ }^{36}$. Es interesante señalar que la "parental responsability" puede ser o no, compartida ("sharing parental responsability"). Esta figura lleva a que determinadas actuaciones sean necesariamente conjuntas, como el cambio de domicilio de una ciudad a otra, y otras puedan ser indistintas en el sentido que no necesitan la información, ni autorización del otro padre (independientemente del eventual derecho a veto del otro padre, custodio o no) ${ }^{37}$. Ello se articula, conforme a la Comisión de elaboración de la ley, para lograr que ambos padres participen en la formación de sus hijos ${ }^{38}$. Estos casos son relevantes por cuanto ellos pueden ser asimilaros a la corresponsabilidad, contemplada en el artículo 224 Código Civil de Chile.

\footnotetext{
${ }^{35}$ Código de la Niñez y la Adolescencia (2014). A principios del 2016 ingresó a estudio de la Comisión de Constitución y Códigos del Senado uruguayo un Proyecto de Reforma por el cual se busca establecer la custodia compartida como régimen legal, supletorio y preferente. El Proyecto busca que "Cuando los padres pongan fin a la relación que los unía, la tenencia de los hijos será preceptivamente, es decir de cumplimiento obligatorio, compartida", y promover la custodia compartida con oposición de uno de los padres. Este Proyecto de Ley precisamente es una respuesta a una sentencia de la Corte Suprema, de 20 de octubre de 2014, "AA C/ BB - VISITAS - CASACION", IUE: 2-3463/2009, que casó una sentencia de la Corte de Apelaciones por la que se concedía una custodia compartida aduciendo la fuerte conflictividad de los padres. ("Sentencia de Tenencia Compartida !!! :: TPNHY", 2019)

${ }^{36}$ Lowe y Douglas (2015), a este respecto, señalan que: "In the absence of an agreed list it suggested that parental responsibility comprises at least the following: - Bringing up the child. - Having contact with the child. - Protecting and maintaining the child. - Disciplining the child. - Determining and providing for the child's education. - Determining the child's religion. -Consenting to the child's medical treatment. - Consenting to the child's marriage - Consenting to the child's adoption. -Vetoing the issue of a child's passport. - Taking the child outside the United Kingdom and consenting to the child's emigration. - Administering the child's property. -Naming the child. - Representing the child in legal proceedings. - Disposing of the child's corpse. - Appointing a guardian for the child" (pp. 337-338).

${ }^{37}$ Ello dependerá del alcance de la resolución judicial que concede esta figura (Lowe y Gillian, 2015, p. 393).

${ }^{38} \mathrm{Sin}$ perjuicio que ello no ha estado exento de polémica, como se aprecia del caso $\operatorname{Re} G$ fallado por la Corte de Apelaciones. (Lowe y Gillian, 2015, p. 393).
} 
Nótese que la norma -no se trata sólo de un principio- establece que ambos padres, independientemente de que estén separados, "participarán en forma activa, equitativa y permanente en la crianza y educación de sus hijos".

Las demandas de custodia compartida, que son solicitadas por un padre con la oposición del otro, deben ser acogidas por una "share residence order"39 o "joint physical custody" ${ }^{40}$. La "share residence order" comienza ser acogida por la jurisprudencia inglesa a raíz de un fallo del juez Ward JL, como una custodia compartida con residencia alternada. Su aplicación, desde su reconocimiento por tribunales a mediados de los noventa, se ha ido extendiendo mediante sucesivas modificaciones jurisprudenciales. El primer caso en que se da lugar a estas órdenes procedió cuando el padre, que convivía con el niño, niña o adolescente, desconoció la responsabilidad parental del padre no custodio. Así, en el 2004 en la causa A v A (Children, shared residence) se concede una de estas órdenes a favor del padre no custodio, dado que la madre -que era el padre custodio- estaba decidiendo unitariamente los aspectos relacionados con la educación y salud del niño. Nótese que en estos casos se concibe como una sanción al padre custodio infractor de los derechos del padre no custodio. En otras palabras, la custodia compartida, con oposición de un padre, se comienza a conceder por tribunales cuando el padre custodio desconoce la "parental responsability" (la corresponsabilidad entre nosotros) del padre no custodio ("non resident parents"). Naturalmente, que esta es una mirada limitada hacia la figura. Por ello, posteriormente, la "shared residence" sólo se concede en casos en que el interés superior del niño, niña o adolescente lo permita, pero todavía de una forma muy justificada o restrictiva (Nikolina, 2015, pp. 49,67) ${ }^{41}$. Finalmente, en una etapa posterior, la custodia compartida se comenzó a imponer, aún en caso de conflicto entre los padres, y se ha rechazado que ella se deba dar en circunstancias excepcionales ${ }^{42}$. También es destacable que la Reforma, introducida a la sección 11 por una Ley de 1989,

\footnotetext{
${ }^{39}$ Esta acción es entablada por uno de los padres, en caso que el hijo resida con el otro, para los efectos de establecer una residencia alternada. Nikolina $(2015$, p. 51) y Hayden $(2011$, p. 7).

${ }^{40}$ Gilmore (2006).

${ }^{41}$ En igual sentido, Hayden (2011, p.18), cita a Hale y Wood, que señalan: "Given the negative tone of these passages it is unsurprising that authorities shortly after the coming into force of the legislation revealed an unwillingness to make shared residence orders.

However, as case law has evolved in the English courts, it appears to be the case that the shared residence order has transformed from a rare species to a 'must have', particularly for the nonresident parent and irrespective of whether the children's time is divided equally between the homes". De igual manera Hayden (2011, p. 20), ordena varios casos en los que la jurisprudencia no da lugar a la custodia compartida con oposición de uno de los padres, como cuando el niño, niña o adolescente no quiere la custodia compartida [Re A children, shared residence], cuando las motivaciones de la demanda son impropias [Re K, Shared Residence Order], o simplemente atenta contra el propio menor [In Re M, Children, Residence Order].

${ }^{42}$ En este sentido, Hayden (2001) indica que: "Nevertheless, it appears that even without a legislative presumption of shared residence or even shared parenting at this stage the English Courts of their own volition appear to be finding creative ways in order to ensure that the most likely outcome of a residence application in the majority of cases will be a shared residence order, absent of a very good reason why not, although the equal division of time between two homes remains a rarity" (p. 21).
} 
por una Ley de 22 de octubre del 2014, facultó a los jueces a decretar una "child arrangements order". En el Proyecto de Ley se discutió que no se quería otorgar a la custodia compartida una presunción como forma preferente de desarrollo del interés superior, que llevase a una división equitativa del tiempo entre los padres, sino a establecer una regla de distribución del tiempo de acuerdo a la realidad de cada familia y las circunstancias concretas del niño, niña o adolescente ${ }^{43}$.

\section{A modo de síntesis respecto del derecho extranjero}

El Derecho español y del Reino Unido son especialmente relevantes, respecto de las etapas en que se acepta el cuidado personal compartido con oposición de un padre, sin que esta figura estuviese reconocida directamente por la ley como forma de aplicación del principio del interés superior. Ello aconteció en España, antes de la Reforma del 2005 -e incluso después con el rechazo a entender que se trata de un régimen excepcional-, y en el Reino Unido, antes de la Reforma del 2014. El primer caso es interesante por cuanto los intentos de restringir la aplicación de esta figura, que consagrara el actual apartado 8 del art. 92 del Código Civil Español, no prosperaron, desechándose su carácter excepcional. Otro tanto sucede en el Reino Unido en que, antes de la referida Reforma, los jueces entendieron estar facultados -a pesar de la falta de norma expresa, como en el caso chileno a este respecto- para conceder el cuidado personal compartido con oposición. Para ello se recurrió a los principios del interés superior y de la corresponsabilidad, pero concretándolos al caso específico. En el caso español se han ordenado estos criterios en tres circunstancias que el juez debe valorar: i) las aptitudes personales de los progenitores; ii) la proximidad de domicilios y iii) la opinión del niño, niña o adolescente. Entre ellos son especialmente relevantes las conclusiones jurisprudenciales en torno al nivel de conflictividad entre los padres. La conflictividad, de transformarse en un criterio fundamental, se ha convertido más bien en un criterio que se toma en consideración cuando se afecta negativamente al niño, niña o adolescente. En cambio, en la casuística del Reino Unido se han destacado cuatro formas específicas de cuidado compartido con oposición: i) como sanción al padre no custodio; ii) como forma supletoria de hacer efectivo el interés superior -es decir, de no haber otra forma mejor de adoptar la mejor opción para el niño, niña o adolescente- ${ }^{44}$, iii) como criterio más bien general y, iv) finalmen-

\footnotetext{
${ }^{43}$ Entre los aspectos que debe considerar el tribunal, conforme a la Reforma, están los siguientes: "(a) the ascertainable wishes and feelings of the child concerned (considered in the light of his age and understanding ; (b) his physical, emotional and educational needs; (c) the likely effect on him of any change in his circumstances; (d) his age, sex, background and characteristics of his which the court considerers relevant ; e) any harm which he has suffered or is at risk of suffering; f) how capable each of his parents, and any other person in relation to whom the court considers the question to be relevant, is of meeting his needs; $g$ ) the range of powers available to the court under this Act in the proceedings in question" (Section 11, (3)) (Herring, Probert, and Gilmore, 2012, pp.80-81) .

${ }^{44}$ Las dos primeras formas de aplicación se desarrollaron en la jurisprudencia temprana y son formas muy restrictivas de custodia compartida con oposición.
} 
te, dada la Reforma del 2014, como un criterio que no necesariamente significa un reparto temporal equitativo entre los padres, sino que atiende a facultades y deberes específicos, como educación, necesidades afectivas, riesgo, etc.

\section{La custodia compartida con oposición en el Derecho chileno}

La Ley N²0.680 del 2013 actualizó la regulación de los deberes y facultades de filiación de los padres, regulando expresamente únicamente la custodia compartida de común acuerdo, y no refiriéndose a la custodia compartida con oposición. También es necesario recalcar que uno de los Proyectos de reforma contemplaba la custodia compartida como régimen legal general, supletorio y privilegiado, y otro la contemplaba como régimen especial.

Para analizar la regulación chilena respecto de la custodia compartida con oposición de uno de los padres se analizarán los siguientes aspectos: lo que la doctrina y jurisprudencia chilenas han señalado respecto de la custodia compartida con oposición y los argumentos a favor de esta figura.

\subsection{Posición de la doctrina y jurisprudencias chilenas frente a la custodia compartida con oposición}

La doctrina chilena a pesar de señalar que, a diferencia de otros ordenamientos jurídicos, nuestro Derecho no ha distinguido claramente entre deberesfacultades conjuntos, e indistintos (exclusivos del padre custodio, por una parte, y del no custodio por la otra), ha comenzado a entender que a través de la autoridad parental existe un ámbito conjunto de actuación de los padres, que opera sobre todo en caso de separación ${ }^{45}$. Sin perjuicio de lo cual, la mayoría de los autores señalan que la Reforma del 2013 simplemente no habilitó a los jueces para decretar facultades y deberes conjuntos, ni tampoco para decretar el cuidado personal compartido con oposición de uno de los padres. Acuña (2016) señala, a este respecto, que: "no se ha establecido éste ${ }^{46}$ como modalidad prioritaria o preferente, pues no se instituye como una consecuencia legal de la vida separada de los padres, no está dentro de las opciones de regulación judicial del cuidado personal de los menores" (p. 491). Lathrop Gómez (2017) plantea una posición similar: "Así, en Chile es posible pactar cuidado personal compartido, pero no puede el Juez ordenarlo aunque lo solicite uno de los progenitores" (p. 159) ${ }^{47}$. Rodríguez Pinto (2014) entiende que, a pesar que el artículo 224 Código

\footnotetext{
${ }^{45}$ Este planteamiento aún no es general, ver Barcia Lehmann, R. (2011) y Otárola Espinoza (2013).

${ }^{46}$ Se refiere al cuidado compartido.

${ }^{47}$ Una opinión más matizada plantea Negroni Vera (2014), por cuanto entiende que el principio de la corresponsabilidad debe tener alguna incidencia en la asignación en los deberes y facultades de filiación. Sin embargo, se plantea en contra de la aplicación del cuidado personal compartido con oposición de uno de los padres, señalando que: "La modificación introducida por la ley 20680, fortalece tam-
} 
Civil de Chile consagra el principio de la corresponsabilidad, el juez no puede recurrir a éste como regla de atribución ${ }^{48}$. A su vez, Tapia Rodríguez (2014) señala que, dada la regulación de la Ley $N^{\circ} 20.680$, la custodia compartida con oposición no es posible. El fundamento de su posición consiste en que nuestra legislación sólo se permite que el juez dé lugar a la custodia compartida de común acuerdo entre los padres conforme a lo establecido en el artículo 225 del Código Civil de Chile. Para Tapia Rodríguez (2014), el Derecho chileno habría establecido una suerte de "derecho a veto" de un padre sobre otro en la custodia compartida con oposición ${ }^{49}$. En realidad estos argumentos si bien atendibles no son decisivos, como se desprende de la Historia Fidedigna de la Ley $\mathrm{N}^{\circ} 20.680$, por cuanto la custodia compartida que se desechó es la con oposición de uno de los padres.

La jurisprudencia también se ha inclinado en contra de esta posibilidad, en los siguientes términos:

a) En la causa caratulada "F con V", RIT C-5984-2013, Primer Juzgado de Familia de Santiago, la Corte Suprema resolvió un recurso de casación en el fondo, mediante sentencia de 10 de noviembre del 2015, Rol Ingreso de Corte $\mathrm{N}^{\circ}$ 4889-15 confirmado la sentencia que desechó demanda de cuidado compartido del padre con oposición de la madre. En el cons. $7^{\circ}$ del fallo se resuelve: “...en consecuencia, los sentenciadores del fondo no han infringido dicha disposición al decidir que el régimen de cuidado compartido no puede ser regulado por vía judicial a través de una sentencia, sino que solo por acuerdo de los padres. Además, como la reforma introducida por la Ley $N^{\circ} 20.680$ al Título IX, Libro I, del Código Civil, en lo que interesa, persigue reforzar la idea que los padres deben asumir de manera plena la responsabilidad que les cabe en la crianza, educación y establecimiento de los hijos, vivan juntos o separados, estableciendo que el principio de corresponsabilidad es un imperativo legal en todos los regímenes de cuidado personal una vez cesada la vida en común, con la finalidad que los padres asuman la responsabilidad de velar por el interés de sus hijos para procurar su mayor realización espiritual y material posible, no se ha conculcado la normativa consagrada en la Convención de los Derechos del Niño...". En realidad la

bién la resolución del conflicto mediante el acuerdo, dándole prioridad al mismo, de tal manera que si los padres quieren asumir un régimen de cuidado compartido, sólo lo pueden regular mediante un acuerdo, el juez no podría imponérselos" (p. 121).

${ }^{48}$ En este sentido señala que: "El principio de corresponsabilidad no autoriza al juez para atribuir judicialmente el cuidado personal a ambos padres separados (cfr. Art. 225, inc $1^{\circ}$ ). El cuidado personal compartido solamente puede establecerse por convención entre ambos padres". (Rodríguez Pinto, 2014, p. 80).

49 Tapia Rodríguez (2013), aunque califica esta situación de negativa, señala refiriéndose al artículo 225: "Por último, el inciso $4^{\circ}$ de ese mismo artículo agrega que los padres que viven separados pueden 'de común acuerdo' determinar que el cuidado personal de los hijos corresponde a 'ambos de forma compartida' (...) el juez carece, según esta regla general, de facultades para asignar el cuidado compartido en ausencia de acuerdo de los padres. Esto es, se otorga a cada padre un derecho a veto, para oponerse y hacer inviable un a cuidado personal compartido que pueda beneficiar a los hijos" (p. 17). Finalmente, Illanes (2014) critica el que, en la legislación chilena, el acuerdo de cuidado compartido no esté necesariamente sujeto autorización judicial. 
sentencia precedente sólo justifica el rechazo a la custodia compartida argumentando que la Ley № 20.680 sólo estableció la custodia compartida de común acuerdo.

b) En la causa caratulada "Z con S", RIT C-314-2014, seguidos ante el Tribunal de Familia de Coyhaique, la Corte Suprema, acogió un recurso de casación en el fondo contra la sentencia de la Corte de Apelaciones de Coyhaique, de 7/04/15, Rol N Ingreso Corte de Apelaciones 8-2015. La sentencia de la Corte Suprema, de 17 de diciembre de 2015, Rol Ingreso Corte № 6320-15, anuló un fallo de la Corte de Apelaciones de Coyhaique que había confirmado un cuidado compartido con oposición de un padre. La sentencia de primera instancia, haciendo una aplicación del principio del interés del niño, decretó -dado que los padres habían convenido en los hechos un cuidado personal alternativo- un cuidado compartido. El razonamiento de los jueces de instancia, a este respecto fue impecable; pero la Corte suprema, acogiendo un recurso de casación en el fondo, negó lugar al cuidado compartido con oposición de un padre. Los fundamentos del fallo anulatorio son tres. El primero es que esta figura no existe y los tribunales inferiores al establecerla trasgredirían el artículo 225 del Código Civil de Chile ${ }^{50}$; el segundo consiste en que Derecho comparado no contemplaría esta figura ${ }^{51} y$, el tercero, señala que esta figura no procede dada la continua conflictividad de los padres ${ }^{52}$. El primer funda-

\footnotetext{
${ }^{50}$ En este sentido en el cons. $7^{\circ}$ del fallo de casación resuelve: "Que, del modo antes expresado, queda claro que la determinación de los sentenciadores en relación a fijar el cuidado compartido a favor del menor de autos, no tomó en consideración el inciso tercero del artículo 225 que señala expresamente que 'En cualquiera de los casos establecidos en este artículo, cuando las circunstancias lo requieran y el interés superior del hijo lo haga conveniente, el juez podrá atribuir el cuidado personal del hijo al otro de los padres, o radicarlo en uno solo de ellos, si por acuerdo existiere alguna forma de ejercicio compartido'. Del cual se deduce sin ninguna duda, que el juez no tiene atribución para fijar como forma de ejercer el cuidado personal de un hijo, el de hacerlo en forma de cuidado compartido, ya que la ley establece claramente todas las posibles soluciones que puede tomar el juez, en los casos sometidos a su decisión". Y todavía de forma más clara, en la sentencia de reemplazo, resuelve en referencia a que la figura no existiría en el Derecho comparado: "Quinto: Que es por lo anterior que el legislador no le dio atribuciones al juez para fijar el cuidado compartido, porque los padres que llevan sus disputas a los tribunales y prefieren que un extraño decida en lugar de ellos mismos, quien está mejor capacitado para ejercer el cuidado de sus hijos o que decida en definitiva al cuidado de quien sus hijos estarán mejor; no son los padres de los que habla la doctrina, estos que se encuentran en un alto grado de armonía y cooperación".

${ }^{51}$ En la sentencia de reemplazo, la Corte Suprema resuelve: "Cuarto: Que la doctrina y el derecho extranjero están de acuerdo en señalar, respecto al cuidado compartido, que 'Otro rasgo importante de esta institución es su fuente en la convención de los padres. Los acuerdos de tuición conjunta o alternada desde su introducción en los años 1980 son convenios entre los padres. Requieren el mutuo acuerdo entre progenitores. Lo que resulta difícil de aceptar es que los tribunales de familia decreten estos sistemas contra la voluntad de uno de los padres. En el ámbito norteamericano, hay numerosos estudios que desaconsejan la tuición compartida si no hay un alto grado de armonía y cooperación entre los padres'". Rodríguez Pinto (2010, p. 97).

52 En la sentencia de reemplazo respecto a la conflictividad de los padres se resuelve lo siguiente: "Séptimo: Que en el caso de marras, aun cuando se quisiera interpretar el artículo 225 entendiendo que el juez sí tiene atribución para fijar la custodia compartida, los padres, han llevado múltiples problemas para ser resueltos por los tribunales, por ser ellos mismos incapaces; lo que no augura que el cuidado compartido sea el mejor régimen para, ya que se prevén innumerables disputas entre los padres, lo que dista de ser
} 
mento del fallo no se hace cargo que no existe ninguna norma prohibitiva a este respecto y que los principios del interés superior del niño, niña o adolescente y de corresponsabilidad llevan a que el juez pueda aplicar figuras reconocidas por el Derecho, como el cuidado compartido con oposición de un padre, en la medida que ello vaya en el mejor interés del niño, niña o adolescente ${ }^{53}$. Pero sobre todo la sentencia yerra si se recurre a la historia fidedigna de la Ley $\mathrm{N}^{\circ}$ 20.680. Dicho estudio permitiría concluir que el Congreso desechó la custodia compartida con oposición de uno de los padres como sanción al padre custodio, como se analiza en detalle más adelante. Pero, también, la sentencia yerra, al referirse al Derecho comparado porque esta figura es ampliamente acogida en éste ${ }^{54}$. Nótese que con normas similares a las nuestras, es decir, con regulaciones que establecen la corresponsabilidad como en el caso del Reino Unido-, o incluso que ni siquiera establecen este principio, como la española, los tribunales han admitido el cuidado personal compartido con oposición no sólo como régimen excepcional, sino como régimen general (el presente trabajo intenta la introducción en nuestro Derecho de la primera opción, es decir, en concreto y no en abstracto). Finalmente, el tercer sustento, el grado de conflictividad, debió ser objeto de un análisis más profundo. En la doctrina y jurisprudencia española el grado de conflictividad sólo es relevante si hace imposible el cuidado compartido, y en el Reino Unido incluso es un criterio para dar lugar a la custodia compartida con oposición (custodia compartida como una sanción al padre no custodio que no respetaba los derechos del padre no custodio). Y, en este sentido, lo realmente criticable es que la prueba del proceso no aborda el grado de conflictividad, como punto de prueba. Ello redunda en que las tribunales no tienen las herramientas para determinar si el nivel de conflictividad conduce a que el cuidado personal compartida sea dañino para el niño, niña o adolescente.

c) La sentencia de la Corte Suprema, de 29 de septiembre de 2015, Rol Ingreso Corte No 22.881-2014, en la causa caratulada "G con R", RIT C-1101-2014, seguida ante el Tercer Juzgado de Familia de Santiago, anuló tanto la resolución de 28 de febrero de 2014, que no dio curso a la demanda de cuidado personal compartido, como la sentencia que confirma dicho fallo de la Corte de Apelaciones de Santiago, de 30 de junio de 2014. Las sentencias anuladas, aplicando el artículo $54.3^{\circ}$ Los Tribunales de Familia, realizan un control de admisibi-

aquellos padres aptos para llevar exitosamente adelante este tipo de régimen, por lo cual no será esta la mejor forma de proteger la estabilidad emocional del niño de autos".

${ }^{53}$ Nótese que esta es una interpretación bastante restrictiva de la custodia compartida con oposición, por cuanto supone que ella es la mejor posibilidad para el niño, niña o adolescente en concreto, y no en abstracto.

${ }^{54}$ En este sentido en el Reino Unido los tribunales pueden conceder una custodia compartida ("shared residence") en los casos en que el interés superior del niño en concreto lo justifique, y uno de ellos es como sanción al padre custodio que impide el régimen comunicacional con el padre custodio.( Nikolina, 2015, p. 25). 
lidad que las condujo a desechar la demanda. A este respecto la sentencia de la Corte Suprema resolvió: "5० Que, por lo tanto, si bien el control de admisibilidad en los términos señalados en el inciso $3^{\circ}$ del artículo 54-1 de la Ley $N^{\circ} 19.968$ dice relación con el derecho sustantivo aplicable al caso concreto, no puede ejercerse cuando la pretensión que se formula no está rechazada de forma categórica en la ley de modo tal que impida de manera absoluta, explícita y directa, adoptar cualquier decisión de orden jurisdiccional que pueda solucionar el conflicto jurídico planteado de orden familiar, que, en ese contexto, necesariamente habrá de ser resuelto en la sentencia definitiva que debe fundarse en un proceso previo legalmente tramitado, tal como lo garantiza el inciso $5^{\circ}$ del numeral 3 del artículo 19 de la Constitución Política de la República. Una conclusión en sentido contrario, además, contraría la regla de la inexcusabilidad consagrada en el inciso $2^{\circ} \mathrm{del}$ artículo 76 de la Carta Fundamental y en el inciso $2^{\circ}$ del artículo 10 del Código Orgánico de Tribunales, pues, en definitiva, el tribunal aparece rechazando la intervención reclamada en un asunto que por ley se encuentra entregado a su conocimiento y resolución; $6^{\circ}$ Que, por consiguiente, se debe concluir que los jueces del fondo al confirmar la resolución apelada incurrieron en el error de derecho denunciado; razón por la que el recurso debe ser acogido"55. En esta causa la demandante también recurrió, ante el Tribunal Constitucional de Chile, de inconstitucionalidad del artículo $225.3^{\circ}$ Código Civil de Chile (establece la regla legal y supletoria de cuidado en caso de disputa de los padres). El referido tribunal, mediante fallo de 16 de junio del 2015, Rol № 2.699-2014, rechazó el referido recurso, y además entendió que los Tribunales de Familia no tienen facultades para conceder el cuidado personal compartido con oposición ${ }^{56}$. El rechazo al cuidado personal compartido con oposición se sustenta por el Tribunal Constitucional de Chile en los siguientes argumentos: el principio de la corresponsabilidad no debe confundirse con el cuidado personal compartido, por cuanto en cualquier régimen de cuidado rige el referido principio; y el cuidado personal compartido sólo puede tener su origen en al acuerdo de los padres, por aplicación del artículo $225.1^{\circ}, 3^{\circ}$ y $4^{\circ}$ Código Civil de Chile ${ }^{57}$. Ambos fundamentos son difícilmente sostenibles. Ello por cuanto lo que se debe analizar es: ¿en qué casos procede el cuidado personal con oposición como aplicación de la corresponsabilidad?; ello es independiente que, en la mayoría

\footnotetext{
${ }^{55}$ Sin perjuicio de lo anterior, el fallo contó con los votos disidentes de la Ministra Andrea Muñoz y de la abogada integrante Leonor Etcheberry, quienes fueron de opinión de rechazar el recurso, porque el inciso $3^{\circ}$ del artículo 54-1 de la Ley № 19.968 contempla un control de admisibilidad que no solo debe limitarse al examen del cumplimiento de los requisitos formales de la demanda, sino que debe extenderse al análisis del derecho sustantivo que sirve de fundamento a la pretensión, en el caso concreto y por tratarse de una demanda de cuidado personal compartido, a lo dispuesto en el inciso $2^{\circ}$ del artículo 225 del Código Civil que sólo lo contempla si existe acuerdo en ese sentido entre los padres, hipótesis que no concurre.

${ }^{56}$ (G con R, 22881-2014, Corte Suprema 29 de septiembre de 2015, cons. 7 y 8 )

${ }^{57}$ Además el Tribunal Constitucional de Chile trae a colación la opinión ya transcrita de dos profesores de Derecho Civil. Tapia y Rodríguez.
} 
de los juicios, la relación directa y regular deba aplicarse conforme al principio de la corresponsabilidad como por lo demás preceptúa expresamente el artículo $229.4^{\circ}$ Código Civil de Chile. El segundo argumento es increíblemente débil porque como se verá no existe prohibición alguna, ni expresa, ni tácita en los incisos que se invocan, ni el Proyecto de la Ley $\mathrm{N}^{\circ} 20.680$, que impida que el juez pueda dar lugar al cuidado personal compartido en los casos que esta sea lo mejor para el niño, niña o adolescente.

En atención a la posición mantenida por la escasa doctrina, que se ha referido a este tema, y la jurisprudencia precedente es necesario referirse a la Historia de la Ley $\mathrm{n}^{\circ} 20.680$ del 2013. El Proyecto de Ley, que dio lugar a la Ley $\mathrm{N}^{\circ} 20.680$, sufrió varias mutaciones en su aprobación y de todos los Proyectos, que se propusieron respecto de esta ley, quedaron en tramitación los dos siguientes: el de los ex diputados Álvaro Escobar y otros (Boletín n 5917/18, de 12 de junio del 2008), por una parte, y el de iniciativa del Diputado Gabriel Ascencio y otros (Boletín 7007-18, de 29 de junio del 2010) ${ }^{58}$, por la otra. Así, tenemos que, conforme al Boletín del Congreso №5917/18, el Proyecto de artículo 225 establecía un cuidado personal compartido, aún después de la separación de los padres, y que facultaba al juez a decretar el cuidado personal compartido ${ }^{59}$. Posteriormente, una indicación substitutiva del Ejecutivo no dejaría a la custodia compartida como régimen legal supletorio ${ }^{60}$. A ello se puede agregar que el Segundo Informe de la Comisión de Familia, de 28 de junio de 2011, señaló, respecto del cuidado personal compartido como regla legal supletoria, que: "Dado que las relaciones y circunstancias familiares son tan diversas, no puede establecerse como regla supletoria el cuidado personal compartido, como tampoco afirmarse a priori que ésta constituya la mejor alternativa"61. Sin embargo, la referida indicación substitutiva permitía que se diera lugar al cuidado personal con oposición por resolución judicial, como sanción al padre custodio. Así, el Proyecto contemplaba

\footnotetext{
${ }^{58}$ Este Proyecto de Ley era distinto de los anteriores por cuanto mantenía la regla de la superioridad de la madre, como solución legal subsidiaria, y permitía al juez decretar la custodia compartida con oposición. El Proyecto generó una gran discusión en el Senado, en que participaron Alvear, Saffirio, Tumas, Walker, etc. (Introduce modificaciones en el Código Civil, en relación al cuidado personal de los hijos. Boletín $\left.N^{\circ} 7007-18,2010\right)$

${ }^{59}$ En este sentido la referida norma era del siguiente tenor:

"Artículo 225. Si los padres viven separados, el cuidado personal de los hijos corresponderá en principio a ambos padres en forma compartida. Si no hubiere acuerdo en adoptar el cuidado compartido y surgiere disputa sobre cual padre tendrá la tuición, el juez decidirá a solicitud de cualquiera de ellos cu[á]l de los padres tendrá a su cargo el cuidado personal de los hijos". (Informe de la comisión de familia referido a dos proyectos de ley que modifican normas del código civil en materia de cuidado personal de los hijos, 2018)

${ }^{60}$ Así se formula en Introduce modificaciones al Código Civil y a otros cuerpos legales, con el objeto de proteger la integridad del menor en caso de que sus padres vivan separados. Boletín $N^{\circ} 5917$ 18.(2008, Of., $\mathrm{N}^{\circ} 001-359$, p.5).

${ }^{61}$ En este sentido definía el cuidado personal compartido como: "El cuidado personal compartido, acordado por las partes o decretado judicialmente, es el derecho y el deber de amparar, defender y cuidar la persona del hijo o hija menor de edad y participar en su crianza y educación, ejercido conjuntamente por el padre y la madre que viven separados". (Biblioteca del Congreso Nacional de Chile, 2019, p. 10)
} 
esta opción en el artículo $224.4^{\circ}$, en los siguientes términos: "velando por el interés superior del hijo, podrá el juez entregar el cuidado personal a ambos padres, cuando el padre custodio impidiere o dificultare injustificadamente, el ejercicio de la relación directa y regular del padre no custodio con el hijo o hijos, sea que ésta se haya establecido de común acuerdo o decretado judicialmente. También podrá entregarlo cuando el padre custodio realice falsas denuncias o demandas a fin de perjudicar al no custodio $y$ obtener beneficios económicos" ${ }^{\prime \prime 2}$. Esta forma de entender la custodia compartida con oposición no prosperó. En contra de ella se estuvieron el encargado de la Protección Legal del Fondo de las Naciones Unidas para la Infancia (UNICEF), el profesor Nicolás Espejo, y las profesoras Fabiola Lathrop y Sara Rodríguez. Todos estos autores coincidieron en que la custodia compartida no puede concebirse como una sanción al padre custodio ${ }^{63}$. En la Segunda Indicación del Ejecutivo, de 20 de diciembre, 2011 (№ 426-359), ya no se considera la custodia compartida con oposición como sanción al padre custodio ${ }^{64}$.

En virtud de las consideraciones precedentes, la Ley № 20.680 desechó el cuidado personal compartido como regla de asignación legal general y supletoria, prefiriendo asignar el cuidado personal a uno de los padres, conforme al interés superior del niño, niña o adolescente (artículos $225.4^{\circ}$ y $225-2$ Código Civil de Chile); no aprobó el cuidado personal con oposición de un padre, como sanción al padre custodio; y reguló el cuidado personal de común acuerdo (artículos $225.1^{\circ}$ Código Civil de Chile). Estas consideraciones llevan a concluir que en realidad no hay una referencia en la Historia de la Ley $\mathrm{N}^{\circ} 20.680$ tajantemente en contra de la custodia compartida con oposición, desde que sólo rechaza una de las formas de custodia compartida con oposición: la custodia compartida con oposición como sanción al padre custodio.

\section{2. ¿Se podría dar lugar al cuidado personal compartido con oposición de uno de los padres en el Derecho chileno?}

Lo primero que se debe aclarar es que, a lo menos en Chile, la custodia compartida con oposición podría aplicarse, conforme a los principios del interés superior del niño, niña o adolescente y de la corresponsabilidad. Ambos principios son plenamente reconocidos en el Derecho chileno y se trata de principios con funciones de interpretación e integración en el Derecho. En este sentido, la custodia compartida debe ser considerada en la medida que uno de los padres lo solicite, no siendo relevante la oposición del otro. La lógica del Derecho de infancia es que los jueces no deben hacer sólo lo que las leyes les ordenan de forma concreta, sino muy por el

\footnotetext{
62 Indicación sustitutiva al Proyecto de Ley que Introduce modificaciones al Código Civil y a otros cuerpos legales, con el objeto de proteger la integridad del menor en caso de que sus padres vivan separados. Boletín Nº 5917 18.(2008, Of., Nº01-359, p.6)

63 (Biblioteca del Congreso Nacional de Chile, 2019, pp. 160. 162 y 165).

${ }^{64}$ (Biblioteca del Congreso Nacional de Chile, 2019, pp. 147-148).
} 
contrario, deben hacer todo aquello que vaya en beneficio del interés superior del niño, niña o adolescente. Por ello el argumento que señala que no está regulada la custodia compartida con oposición no es suficiente, desde que, existiendo la figura de la custodia compartida, los jueces pueden recurrir a ella en la medida que el interés superior del niño, niña o adolescente los impulse a ello. Por otra parte, en la discusión de la Ley $\mathrm{N}^{\circ} 20.680$, hay dos muy buenos argumentos a favor de la custodia compartida con oposición ${ }^{65}$. El primero es que la regla de la custodia compartida, como regla preferente, se desechó precisamente porque se estimó que la custodia exclusiva o compartida debe determinarse en concreto, conforme al interés superior y no cabía establecer una regla exclusiva a este respecto ${ }^{66}$. Esto es importante dado que habría una inclinación en que las formas de asignación del cuidado personal sean concretas y no abstractas. El segundo argumento es que en la discusión de la Ley sólo se desechó una forma concreta de custodia compartida con oposición: la que se decreta como una sanción al padre custodio ${ }^{67}$. Finalmente, el principio inspirador de la Ley $\mathrm{N}^{\circ} 20.680$ es el de la corresponsabilidad, que fue consagrado expresamente en el artículo 224 Código Civil de Chile, que lleva a que los jueces deban establecer los criterios y condiciones específicas conforme a los cuales se puede dar lugar al cuidado personal compartido con oposición. El juez debe solicitar la prueba concreta con relación a este régimen que no sólo debe recaer sobre la conveniencia de adoptarlo, sino que debe ser decretado conforme al mejor desarrollo del niño, niña o adolescente. Y ello exige un esfuerzo adicional de los tribunales de familia, por lo que independientemente que se establezca algún estándar de alternancia -por ejemplo una que establezca una residencia principal- debe acreditarse que dicho régimen en concreto es beneficioso para el niño, niña o adolescente. La legislación sobre cuidado personal, respecto de padres separados, debe otorgar al Juez todas las herramientas necesarias para concretizar de la mejor forma posible el interés superior del niño. Así se ha entendido, en los ordenamientos jurídicos comparados analizados, en que el principio del interés superior lleva a desvincular al juez de las peticiones de las partes, pudiendo y debiendo tomar todas las medidas pertinentes a la protección y desarrollo del niño. La casuística analizada en el presente trabajo, en que se buscaron ordenamientos jurídicos que en su evolución estuvieron en una instancia similar al nuestro, es un aporte en cuanto a las formas de concretizar el interés superior del niño, niña o adolescente y la corresponsabilidad. Entre ellos es destaca-

\footnotetext{
${ }^{65}$ Es de destacar que, a pesar de lo señalado precedentemente, la doctrina chilena no ha estudiado en detalle la custodia compartida con oposición. Y, a este respecto, sólo Illanes (2016) se ha referido tangencialmente a este problema, señalando: "...los estudios hechos a nivel comparado, y que incluso se tuvieron a la vista en la discusión de la ley, estiman que no toda relación conflictiva entre los padres debe ser necesariamente excluyente de la custodia compartida". (p.141).

${ }^{66}$ Ver la trascripción del Informe de la comisión de familia referido a dos proyectos de ley que modifican normas del código civil en materia de cuidado personal de los hijos, Boletines Nº $5917-18$ y $7007-$ 18, Refundidos (2018) reproducido previamente.

${ }^{67}$ En este sentido no se advirtió que la regla actual es todavía más fuerte a este respecto, por cuanto un padre obstructor debería perder el cuidado personal, como ya ha acontecido con algunas sentencias.
} 
ble que el nivel de conflictividad de los padres debe matizarse, y no es un criterio absoluto al momento de evaluar un cuidado personal compartido con oposición. Naturalmente, que el único límite para la toma de decisiones es que las medidas vayan en real beneficio del niño, niña o adolescente (Pinto Andrade, 2009, pp. 56-57). Ahora bien, en el Derecho chileno la declaración judicial de cuidado personal compartido con oposición sólo podría generarse en un procedimiento ordinario de familia, ya sea por demanda o reconvención. Pero, en ambas situaciones, será de vital importancia que el auto de prueba permita que las partes puedan rendir las probanzas tendientes no sólo a acreditar la conveniencia de la custodia compartida, sino a determinar su forma concreta de otorgamiento. A dicho efecto será especialmente relevante tanto escuchar el niño, niña o adolescente, y a los propios padres, como la consignación de sus habilidades parentales para determinar de forma concreta el cuidado personal compartido.

\section{Conclusiones}

1. Los diferentes sistemas jurídicos contemplan distintas reglas generales para los casos en que los padres no se pongan de acuerdo en torno a la custodia, cuidado personal, autoridad parental, etc., recurriendo siempre a alguna regla legal supletoria y preferente. La Convención sobre los Derechos del Niño no impone un criterio a este respecto, pudiendo establecerse una custodia exclusiva, unilateral o indistinta, por una parte, o compartida, por la otra. Independientemente de ello, la Convención sobre los Derechos del Niño lo que exige es que ambos padres participen en la crianza y educación de los hijos (artículo 5) y que se adopten por el Estado -lo que comprende a los jueces-, las medidas que hagan efectivos los derechos reconocidos por la convención (artículo 4). Por ello, en el caso más alejando de una regla de corresponsabilidad más estricta, como lo es la custodia personal exclusiva, se deben tomar ciertos resguardos. En el presente trabajo se analiza uno de ellos -que convive con deberes y facultades conjuntos e indistintos, como los deberes y facultades del padre custodio (custodia principal) y del no custodio (custodia indistinta, en su caso, supervigilancia y control y cooperación y auxilio)-, que es específico: la custodia o cuidado personal compartido con oposición. Desde la perspectiva de los principios del interés superior y de la corresponsabilidad parental, el juez está habilitado para conceder estas custodias, y ello es evidente ya que en muchos casos la situación óptima de desarrollo de derechos de la infancia sólo será posible a través de dicha figura. El juez en su fallo debe ser cuidadoso, midiendo las habilidades parentales de ambos padres, escuchando al niño y analizando si el nivel de conflictividad de los padres es tal que es dañina para el niño, niña o adolescente. 
2. La custodia compartida con oposición se puede conceder, aún en casos de conflictividad entre los padres (propio por lo demás de una separación), pero en estos casos los jueces deben ponderar si dicho régimen será lo mejor para el niño, niña o adolescente.

3. La Historia fidedigna de la Ley $\mathrm{N}^{\circ} \mathbf{2 0 . 6 8 0}$ no es contraria a la custodia compartida con oposición, sino a que ella opere como una sanción para al padre custodio.

4. El que no esté regulado el cuidado personal compartido con oposición directamente por la ley no es óbice, para concederlo, pero para ello es necesario que los principios del interés superior y corresponsabilidad se apliquen de forma concreta al caso que se analiza.

\section{Agradecimientos}

El presente artículo forma parte del Proyecto Regulares de FONDECYT № 1150454 , 2015.

\section{Referencias Bibliográficas}

Acuña San Martín, M. (2016). Relaciones jurídicas entre los padres y el (la) hijo (a). Filiación. En J. Del Picó (Dir.), Derecho de Familia (pp. 423-572). Santiago: Thomson Reuters.

Alcázar Ruiz, R. (2014). Diseño de una escala para la evaluación de la custodia compartida en el ámbito judicial. Estrategia para la validación científica de la escala (ICC) Azarbe, (3), 271-277. Recuperado de http://bit.ly/2mRLrn]

Alascio, L. (2011). La excepcionalidad de la custodia compartida impuesta (art. 92.8 CC). InDret, (2), 25. Recuperado de http://bit.ly/2mO3uLu

Anteproyecto de ley sobre el ejercicio de la corresponsabilidad parental en caso de nulidad divorcio separación. CM 19-7-13, Madrid, España, 19 de julio de 2013. Recuperado de http://bit.ly/2IZf6L9

Barcia Lehmann, R. (2011). Fundamentos del Derecho de familia y de la infancia. Santiago: Thomson Reuters.

Biblioteca del Congreso Nacional de Chile. (2019). Historia de la Ley $N^{\circ} 20.680$ [PDF]. Recuperado de http://bit.ly/2mEluXx 
Bodelón, E. (2012). La custodia compartida desde un análisis de género: estrategias machistas para invisibilizar la violencia en las rupturas familiares. En T. Picontó (Ed.), La custodia compartida a debate (Vol. 56, pp. 131-154). Madrid: Dykinson.

Brasil. Presidência da República. (2002). Código Civil. Recuperado de http://bit.ly/2mVHJJA

Cajigal, I. (2016). La facultad de delegar el ejercicio de la responsabilidad parental. Cuadernos de doctrina judicial de la provincia de la pampa, 8(1), 284-297. Recuperado de http://bit.ly/2ms9lpO

Campuzano, H. (2004). La custodia compartida. Doctrina jurisprudencial de las Audiencias Provinciales. Aranzadi civil (Ed. quincenal), (3), 2479-2512.

Chile, Cámara de diputados. (2018) Informe de la comisión de familia referido a dos proyectos de ley que modifican normas del código civil en materia de cuidado personal de los hijos, Boletines $N^{\circ}$ s 5917-18 y 7007-18, Refundidos. Recuperado de http://bit.ly/2mVHJJA

Chile, Ministerio de Justicia. (2000). Código Civil. Recuperado de http://bcn.cl/1uu74

Chile, Ministerio de Justicia. (1943). Código Orgánico de Tribunales: Ley 7421. Recuperado de http://bcn.cl/1uvpf

Chile, Ministerio Secretaria General de la Presidencia. (1980). Constitución Política de la República. Recuperado de http://bcn.cl/1 uva9

Cruz, B. (2012). La guarda y custodia de los hijos en las crisis matrimoniales. Madrid: La Ley.

Delgado, G. (2010). La custodia de los hijos. La guarda compartida: opción preferente. Cizur Menor: Thomson Reuters.

España, Ministerio de Gracia y Justicia. (1889). Código Civil. Madrid: Gaceta de Madrid. Recuperado de http://bit.ly/2mEwNAg

Espejo, N. (2016). El derecho a la vida familiar, los derechos del niño y la responsabilidad parental. En C. Lepin y M. Gómez de la Torre (Eds.), Estudios de derecho de familia (Vol. 1, pp. 197-209). Santiago: Thomson Reuters.

F con V, 4889-2015 (Corte Suprema 10 de noviembre del 2015).

Fondo de las Naciones Unidas para la Infancia. (1989). Convención sobre los Derechos del Niño. Recuperado de http://bit.ly/2mOhlvR 
France. (2007). Code civil. Recuperado de http://bit.ly/2km2M6W

G con R, 22881-2014 (Corte Suprema 29 de septiembre de 2015). Recuperado de http://bit.ly/2mdMjCQ

Gete-Alonso, M. y Solé, J. (2014). Filiación y potestad parental. Valencia: Tirant lo Blanch.

Guilarte, C. (2014). La concreción del interés del menor en la jurisprudencia del tribunal supremo. Valencia: Tirant lo Blanch.

Gilmore, S. (2006). Contact/shared residence and child well-being: research evidence and its implications for legal decision-making. International journal of law, policy and the family, 20(3), 344-365. https://doi.org.10.1093/lawfam/ebl016

Hayden, A. (2011). Shared custody: a comparative study of the position in Spain and England. InDret, 2011 (1), 32. Recuperado de http://bit.ly/2ny4Dqo

Herrera, M. (2015). Manual de derecho de las familias. Buenos Aires: AbeledoPerrot. Recuperado de http://bit.ly/2odsAE5

Herring, J., Probert, R., y Gilmore, S. (2012). Great debates in family law. Croydon: Palgrave Macmillan.

Illanes, A. (2014). El resguardo de la corresponsabilidad parental en la Reforma de la Ley N² 20.680. En A. Vidal Olivares, G. Severín Fuster, C. Mejías Alonso. (Eds,), Estudios de Derecho Civil (Vol. 10, pp. 299-307). Santiago: Thomson Reuters.

Illanes A. (2016).Incoherencias del régimen de custodia compartida introducido por la Ley N²0.680". En M. Barría Paredes (Coord.), Estudios de Derecho Civil (Vol. 11, pp. 139- 152). Santiago: Thomson Reuters.

Italia. (1942). II Codice Civile Italiano. Recuperado de http://bit.ly/2mMesB|

Lathrop Gómez, F. (2017). El cuidado de los niños después de la separación de sus padres: ¿ayuda a los niños la legislación sobre tiempo de parentalidad compartida?. En F. Lathrop Gómez y N. Espejo Yaksic (Coord.), Responsabilidad parental (pp. 163198). Santiago: Thomson Reuters.

Miranda, M. (2009). La protección de menores: una perspectiva constitucional. En Cuadernos de derecho judicial, (2), 11-70. 
Montero, J. (2001). Guarda y custodia de los hijos: la aplicación práctica del artículo 92 del Código Civil. Valencia: Tirant Lo Blanch.

Negroni Vera, G. (2014). Corresponsabilidad parental un cambio de enfoque radical. Revista de derecho de familia, 1 (1), 103-126.

Ley $N^{\circ} 15 / 2005$, de 8 de julio de 2005, por la que se modifican el Código Civil y la Ley de Enjuiciamiento Civil en materia de separación y divorcio. Boletín Oficial del Estado, Madrid, España, 9 de julio de 2005. Recuperado de http://bit.ly/2nDM9F4

Ley 19.968, de 25 de agosto de 2004, crea los Tribunales de Familia. Diario Oficial de la República de Chile, Santiago, 30 de agosto de 2004. Recuperado de http://bcn.cl/1uw0y

Ley 20.680, de 16 de junio 2013, Introduce modificaciones al Código Civil y a otros cuerpos legales, con el objeto de proteger la integridad del menor en caso de que sus padres vivan separados. Diario Oficial de la República de Chile, 21 de junio 2013. Recuperado de http://bcn.cl/1v8p5

Lowe, N. y Douglas, G. (2015). Bromley's Family Law. Oxford: Oxford University Press.

Nikolina, N. (2015). Divided parents, shared children (Vol. 39). Cambridge: Intersentia.

Notrica, F. y Rodríguez Iturburu, M. (2014). Responsabilidad parental: algunos aspectos trascendentales a la luz del Nuevo Código Civil y Comercial de la Nación. Saldando viejas deudas. En M. Graham y M. Herrera (Dirs.), Derecho de las familias, infancia y adolescencia: una mirada crítica y contemporánea (pp.133-155), Buenos Aires: Infojus. Recuperado de http://bit.ly/2IWyl89.

Otárola Espinoza, Y. (2013). La autoridad paternal conjunta, independiente de quien tiene el cuidado personal de los hijos, si los padres viven separados en Chile. En Anuario IDEJ, 2013, 18-27. Recuperado de http://bit.ly/2mFcpyE

Pellegrini, M. V. (2016). Responsabilidad parental. En M. Herrera, G. Caramelo, S. Picasso (Dirs.), Código Civil y Comercial de la Nación comentado. (Vol. 2, pp. 466-540). Buenos Aires: Infojus. Recuperado de http://bit.ly/2IUDZYq

Pérez Conesa, C. (2016). La custodia compartida. Pamplona: Aranzadi.

Perú, Ministerio de la Mujer y Desarrollo Social. (2000). Código de los niños y adolescentes. Recuperado de http://bit.ly/2oenib8 
Picontó, T. (2010). Ruptura familiar y coparentalidad: un análisis comparado. En su La custodia compartida a debate (Vol. 56, pp. 45-76). Madrid: Dykinson.

Pinto Andrade, C. (2009). La custodia compartida. Barcelona: Bosch.

Poussin, G. y Lamy, A. (2005). Custodia compartida, cómo aprovechar sus ventajas y evitar tropiezos. Madrid: Espasa Calpe.

Proyecto Ley de 12 de junio 2008, Introduce modificaciones al Código Civil y a otros cuerpos legales, con el objeto de proteger la integridad del menor en caso de que sus padres vivan separados. Boletín Nº 5917 18. Recuperado de http://bit.ly/2m7zD08

Proyecto Ley de 29 de junio 2010, Introduce modificaciones en el Código Civil, en relación al cuidado personal de los hijos. Boletín $N^{\circ}$ 7007-18. Recuperado de http://bit.ly/2mdOHtk

Rivera Álvarez, J. M. (2006). La custodia compartida impuesta por el juez a solicitud de uno de los padres una realidad excepcional en las crisis matrimoniales: el párrafo octavo del art. 92 del CC. Acciones e Investigaciones Sociales, (Extra 1), 186. Recuperado de http://bit.ly/2o9gews

Rhoades, H. y Boyd, S. B. (2004). Reforming custody laws: a comparative study. International journal of law, policy and the family, 18(2), 119-146. https://doi.org/10.1093/lawfam/18.2.119

Rodríguez Pinto, M. S. (2010). El cuidado personal de niños y adolescentes, en el nuevo derecho chileno de familia, Santiago: Abedelot-Perrot.

Rodríguez Pinto, M. S. (2014). Nuevas normas sobre cuidado personal, relación directa y regular y patria potestad en el Código Civil chileno. Revista de derecho de familia, 1(1), 77-101.

Sanford, K. (2003) Family law in America. New York (NY): Oxford University Press. https://doi.org/10.1093/acprof:oso/9780199264346.001.0001

Seijas, J., Arroyo, F. y Baena, E. (2015). Recopilación de doctrina jurisprudencial de la sala primera en materia de derecho de familia año 2014. Custodia, traslado de menores y desamparo. En Asociación española de abogados de familia, Nuevos impulsos para el derecho de familia: ponencias del XXII encuentro de la AEAFA (pp. 107-132), Madrid: Sepín. 
Sentencia de Tenencia Compartida !!!: TPNHY. (2019). Recuperado de http://bit.ly/2osleg5

Sentencia del Tribunal Supremo Español, 25 abril 2014, Roj: STS 1699/2014 - ECLI: ES:TS:2014:1699 (Tribunal Supremo. Sala de lo Civil) Recuperado de: http://bit.ly/2mQbThl

Skjørten, K. y Barlindhaug, R. (2007) The Involvement of children in decisions about shared residence. International journal of law, policy and the family, 21(3), 373-385. https://doi.org/10.1093/lawfam/ebm011

Tapia Rodríguez, M. (2013). Actualidad legislativa. Revista chilena de derecho privado, (21), 477-491. https://doi.org/10.4067/s0718-80722013000200022

Uruguay, Cámara de Senadores. (2014). Código de la Niñez y la Adolescencia. Recuperado de http://bit.ly/2nIG5uR

Villagrasa, C. (2010). La custodia compartida en España y en Cataluña: entre deseos y realidades. En T. Picontó (Ed.), La custodia compartida a debate (Vol. 56, pp. 76-99). Madrid: Dykinson.

Z con S, 6320-2015 (Corte Suprema 17 de diciembre de 2015). Recuperado de http://bit.ly/2mWORW7

Zarraluqui, L. (2003). El menor en las crisis familiares. En I. Lázaro, Isabel y I. Mayoral (Coords.), Jornadas sobre derecho de los menores (pp. 159-202). Madrid: Universidad Pontificia de Comillas.

\section{Para citar este artículo bajo Norma APA 6a ed. Barcia Lehmann, R. (2019). La legislación chilena no es contra- ria al cuidado personal compartido con oposición de uno de los padres. Revista de Derecho (Coquimbo. En línea), 26, e3594, http://doi.org/10.22199/issn.0718-9753-2019-0004}

Copyright del articulo: (2019 Rodrigo Barcia

Este es un artículo de acceso abierto, bajo licencia Creative Commons BY 4.0. 